\title{
30 Challenge, conflict and culture: issues for secondary school mathematics educators
}

\author{
Gail Marshall \\ Gail Marshall \& Associates \\ 2393 Broadmont $C t$. \\ Chesterfield, Missouri 63017, USA
}

\begin{abstract}
'Edutainment' software may or may not be appropriate for secondary school mathematics classrooms. Educators should check the epistemological assumptions on which the software is based, as well as the mathematical topics, the pedagogical style and the cultural biases of the software for a goodness of fit with their own goals and objectives. Each of these issues also has implications for equity. Should all students work with the same software products or should different political, social and economic goals be realized for different students? Educators from the industrialized nations as well as those from developing countries will find competing views on these issues create challenges in setting policies for mathematics instruction.
\end{abstract}

\section{Keywords}

Basic skills, culture, curriculum policies, developing countries, edutainment, equity, implications.

\section{INTRODUCTION}

Computers are standard equipment in schools worldwide so the sales potential for educational software has attracted the attention of a wide range of publishers, some of whom have only recently entered the educational marketplace. The software products these newcomers create more closely resemble Hollywood movies than 'traditional' school media. The products, whose lush graphics and sound often overwhelm the educational content, have provoked concern about the future course of secondary school mathematics. 
'Edutainment' - the junction of education and entertainment-is not a new concept. Aesop's fables, Shakespeare's plays and the Grimms' brothers fairy tales are both entertaining and educational. Before we dismiss edutainment we should remember that Clark (1977) said,

"On thinking it over I do see that it is a mistake to draw too sharp a line between entertainment and education. I fancy that education has two complementary aspects." (pps 244-245)

One aspect, according to Clark, is learning what we don't want to do. Clark says this is crucial to maintaining mental activity throughout one's life; the argument usually presented to spur the learning of Latin or geometry. The second aspect, says Clark "is what you learn through delights." We remember also that 'school' and 'play' both derive from the Latin word 'ludens.'

If edutainment software can be worthwhile or not, we should examine several issues related to the design and use of secondary school mathematics software. We should judge software's applicability to our educational goals on more than the fact that the software has an edutainment look and feel. Here are several key issues to be considered in choosing and using software:

- conflict about which epistemology serves as the underlying philosophy for software developers;

- conflict about what mathematics should be taught in secondary schools;

- conflict about how mathematics should be taught; and

- challenges about the look and feel of the software chosen.

For each issue there are groups of psychologists (the clash of the titans), mathematicians (the armies of the night), curriculum specialists and teachers (the voices crying in the wilderness), and software developers (the cultural ambassadors) who have directly or indirectly affected what secondary mathematics students do with computers.

Each issue creates problems of equity. For example, is it equitable that some students use only drill and practice software while other students explore lines and planes with geometry software? The implications of decision making about software choices are many and complex.

\section{MAJOR ISSUES}

\section{The clash of the titans}

Discussions of epistemological issues - how learning is acquired and develops are seldom discussed when IT-based policy making occurs. The educational implications of theories of Locke and Skinner versus Piaget and Bruner are rarely discussed at IT conferences. Either the differences aren't thought important or, since many countries have long espoused a single point of view about learning, 
the issue is regarded as moot. But in some countries competing viewpoints have sparked debate about how IT-based instruction should be designed and delivered.

Teachers have watched the pendulum of opinion swing from behaviorist viewpoint to constructivist viewpoint and back again. Nicholson (1995) and Marshall (1995) have chronicled the debates about behaviorism versus constructivism that animate discussions about IT use in Australia, the United Kingdom and the United States. Developing countries may find themselves facing similar debates and find that ignoring the fundamental assumptions on which the software is based may lead to disagreements between teachers - who must use the software - and decision makers - who make policy that affects the purchase of software. That lack of goodness of fit will compromise efforts to maximize IT's impact as Marshall has pointed out (1993).

The armies of the night

In the United States teachers say that mathematics is whatever is published by the leading textbook publishers. Computation tends to be the daily fare of the majority of American school children, regardless of grade/age level, and only a small percentage of students take courses in geometry, algebra, or calculus. For more than a century the persistence of computation has not abated, even today with the wealth of software products designed to foster geometrical thinking, plausible inference or spatial intelligence.

Hughes (1986), Freudenthal (1973), and many others, have discussed the multiple and competing visions of what mathematics should be taught at what stages in students' mathematical progress. But the mathematicians working alone or in concert on school mathematics curriculum guidelines might as well be an army of the night - invisible to all but the most dedicated seekers. In fact, the views of most mathematicians and mathematics educators are so cloaked in darkness that the average secondary school mathematics teacher in the USA is unaware of the different and competing visions of what topics secondary school mathematics should encompass.

It would be interesting to list the topics mathematicians view as essential to the modern day mathematics curriculum and compare those lists with the topics covered in the current crop of 'edutainment' software. We might find that less than ten percent of the recommended topics are covered. This means that schools adopting and using only 'edutainment' products for IT-based secondary mathematics instruction will fall far short of the experiences recommended by the mathematics community.

The voices crying in the wilderness

Proponents of reform in teaching mathematics, for example diSessa (1988), envision classrooms where students are actively engaged in solving novel and complex problems on their own or in collaboration with other students. But many technology-equipped classroom are still based on historical traditions governing their countries' classroom practice for decades or centuries. Recitation, rote and 
repetitive exercises in a competitive environment that characterized book and pencil settings are replicated in IT settings.

This acceptance of the status quo plus technology has served as a model not only for schools in the industrialized nations but also for schools in developing countries whose decision makers are often persuaded by the fashions promoted by aid agencies sponsoring specific educational products and practices fashionable in one or another part of the industrialized world (Papadopoulos, 1994).

Current strategies for teaching with software ought to be analyzed with an eye toward the ways the desirable titles can best be presented to students in order to maximize the software's impact and stories of how the changes in teaching strategies required to achieve that maximization ought to be a regular feature of professional publications.

\section{The cultural ambassadors}

American software designers are sublimely careless about the design of their software. Their attitude assumes that if they manufacture it, educators will buy it - regardless of intrinsic worth. This cavalier attitude results in depictions of human beings that fail to reflect the ethnic diversity in the United States, let alone worldwide diversity. Even when animals are used as characters the animals either tend to be those found in America or are Disneyesque depictions of animals found on other continents. Settings and situations reflect an Amerocentric bias. 'stores' and 'neighborhoods' look like a television version of America instead of resembling actual American settings or scenes familiar in other countries.

The assumption of USA-based 'edutainment' developers that the pace, content, feedback style and curricular content of current software meets the needs of a worldwide audience is based on a singular (and most often behaviorist) view of education. A major question is whether the mathematics education community worldwide could or would provide alternative visions of software design. A related question is whether, given the enormous profitability of current software, software publishers would pay any attention to the mathematics community or view the worldwide market as a captive audience. Certainly a first step might be a serious analysis of current software with a rubric which is oriented toward intellectual and cultural norms instead of technological norms. Squires' (1996) discussion of 'false complexity' in current software design is a good jumping off place for this endeavour.

\section{EQUAL TIME OR UNEQUAL OPPORTUNITIES?}

If the issues were not sufficiently complicated, each choice - which view of learning and development, what to teach and how to teach it, how the software should look and feel - has equity implications. Sutton's review (1991) of the research on equity says that equity is a qualitative judgment about the justice of decisions. Collis (1993) presented equity issues as a set of decisions about students' access to hardware regardless of gender, class or race. Of equal or 
greater importance is the quality and equality of students' experiences with technology.

\section{Epistemology and equity}

A choice of epistemology affects which students are served by what software. We know that students attending schools in America's inner cities usually receive only drill and practice software while students in the suburbs experience a wider range of software options. Inner city decision makers believe their students have been deprived; not only financially but also intellectually, a view that was widely contested in the 70's by, for example, Ginsburg (1972).

Current policy in the United Kingdom suggests that years of investigative learning, prompted by constructivist theory, has led to shortcomings in students' mathematical performance. A concentration on number and only number has been mandated - a decision that is unpopular with many teachers and curriculum specialists but promises to reorient how students in many schools use technology. So an adherence to one or another learning theory leads to wide ranging conflicts about software choices.

A full scale analysis of the implications of software choices - drill vs. problem solving, for example - must be available for decision makers.

\section{Mathematical topics and equity}

The choice of what mathematical topics will be presented by software has profound implications for students' futures. If computation is the funnel through which students must flow before they can learn any other mathematics topics then problems of equity for race, class and gender will persist. Research indicates that girls and young women need experiences with spatial relations in order to work well with higher level mathematical topics. Urban children from industrialised countries as well as children from developing countries need to be working with the same topics as children who are using technology for problem solving, database exploration and geometrical understanding. A reliance on much of the current 'edutainment' software will not provide the necessary range of mathematical opportunities for groups of students whose subsequent life experiences may suffer in consequence.

An analysis of the goodness of fit between what software accomplishes and the perceived skills and needs of student for the 21st Century is needed as a planning tool for schools as they adopt new software.

\section{Mathematics teaching and equity}

Government planners, industry leaders and social commentators tell us that today's students need to develop a wide range of skills and need to learn to employ those skills in a broad range of settings. Collaboration as well as competition must be nurtured. Students at all economic levels and in all age groups must learn how to solve problems and must learn the variety of skills that will be required to cope in an increasingly technology-centred global market place. This means that the way mathematics is taught must be changed to equip 
all students to function productively in the post-school years. To the extent that mathematics classrooms fail to equip students for the new workplace, they fail to provide equitable experiences for their students.

An analysis of what constitutes 'good' mathematics teaching for a wide range of students and an analysis of how all kinds of students learn from various mathematics software products is needed to guide decision makers.

\section{Software design and equity}

All children have a right to see their own cultures and experiences depicted in the educational materials they work with. Equity means that students in Africa have just as likely a chance of seeing mathematics problems posed in contexts that reflect their day-to-day experiences as American students do. Equity means that girls and young women have software designed in such a way as to structure learning experiences in ways that have been shown to enhance their grasp of the underlying mathematics. Equity means that colours, sounds and icons have been used in ways that respect the traditions and shibboleths of all students. Current 'edutainment' software doesn't acknowledge the diverse musical, visual and pedagogical heritages of students.

An analysis of the impact of software design and the 'look and feel' of each screen is essential and analyses of possible cultural biases displayed in software design are needed to provoke in software producers a higher level of awareness of the multiple audiences world-wide.

\section{POLICIES AND PROBLEMS}

Decisions about mathematics software affect political, economic, social and cultural policies within and across countries. The results of change are complex, cause conflict for any country and often have unpredictable consequences (Marshall, 1993). Changes prompted by the introduction and use of software are no different from other types of educational innovations.

Similarly, questions about who will or should produce software for what platforms under what types of working conditions - within a country, across region - abound. How should the development be funded: out of government funds or by private entrepreneurs? What models of teaching and learning will be used and how consonant are those models with good practice?

We must also take into account the extent to which the introduction of technology into a village disrupts the traditional patterns. We know, for example, that technology use - especially telecommunications - decreases face to face interactions within a community but increases far-flung interactions. Will the use of current 'edutainment' software conflict with artistic, moral, social and educational values? Will the use of such software fragment communities which have been till now harmonious, co-operative groups? If fragmentation occurs, what results? What of the images presented? Although many of us who developed software back in the early days of software production strove not to use 
'culture specific' graphics with the 'Disneyfication' of software we find a proliferation of western-style characters enacting western-style scenarios. How does that affect the internal models of self which are works in progress for young learners in developing countries?

To further complicate the problem, how does technology use fit in the multiage classrooms or in the oral tradition societies of many developing countries? Will project-centred work calling for co-operation among students be written into the curriculum or will individual competition, especially aided by computer-based drill and practice, be the focal point?

Will mathematics curricula be directed at instrumentalist/vocational oriented goals? Will students be taught databases and spreadsheets because that's where the jobs will be? Or will some, and only, some be 'streamed' to learn programming so as to be a talent pool to attract out-sourcing by the major software developers? Will some or all countries seek to develop talent pools of students skilled in problem solving to challenge the economic supremacy of today's hardware and software giants? How do those goals affect both the city student and the village child? Who gets educationally disenfranchised in those decisions?

\section{CONCLUSION}

If we define equity in broader terms than access to computers, and ask how decisions on software use affect students, we will see that the problem is far more than that which can be addressed by a simple quantitative measure of how much hardware or software is installed in a school or country. Instead, the question is how software will be chosen and used to meet the multiple and competing visions of decision makers and the multiple and competing needs of students? Will current or future 'edutainment' products drive the plans for IT-based use or will the visions of mathematicians drive the design and delivery of IT-based secondary school mathematics instructions? The next round won't necessarily favour the mathematicians and mathematics educators of whatever epistemological or pedagogical persuasion. The marketplace is likely to drive the schools regardless of the schools' plans or pedagogy. But the voices of mathematicians, mathematics educators and learning theorists deserve a place at the table when software is designed as well as when decisions about choosing and using software are made.

\section{REFERENCES}

Clark, K.(1977). The Other Half: A Self Portrait, Harper \& Row, New York.

Collis, B. (1993). Information Technology as a tool for addressing inequities at the intermediate level. In D. Johnson and B. Samways (eds.) Informatics and Changes in Learning. Elsevier Science Publishers North-Holland, Amsterdam. 277-284. 
diSessa, A. (1988). What will it mean to be educated in 2020 ? In $R$ Nickerson and P Zodhiates (eds.) Technology in Education: Looking Toward. Lawrence Erlbaum Associates, Hillsdale, NJ.

Freudenthal, H. (1973). Mathematics as an Educational Task. D. Reidel Publishing Company, Dordrecht, Holland.

Ginsburg, H. (1972). The Myth of the Deprived Child. Prentice-Hall, Englewood Cliffs, NJ.

Hughes, M. (1986). Children and number: Difficulties in learning mathematics. Basil Blackwell, Oxford.

Marshall, G. (1993). Informatics and changes in learning: The American dilemma - Opposing epistemological perspectives and unanswered questions. In D. Johnson and B. Samways (eds.) Informatics and Changes in Learning. Elsevier Science Publishers North-Holland, Amsterdam

Marshall, G. (1995). The ABC's of today's technology decision-making in Australia, the United Kingdom and the United States. Paper presented at the Sixth IFIP World Conference on Computers in Education, Birmingham, England.

Nicholson, P. (1995). Constructivist approaches to tackling economic anthropomorphism in Australian IT education. Paper presented at the Sixth IFIP World Conference on Computers in Education, Birmingham, England.

Papadopoulos, G. (1994). Education 1960-1990: The OECD Perspective, Organization for Economic Co-operation and Development.

Squires, D. (1996). Can Multimedia Support Constructivist Learning? Keynote presentation at the Australian Conference on Computers in Education.

Sutton, R. E. (1991). Equity and computers in the schools: A decade of research. Review of Educational Research, 61(4), 475-503.

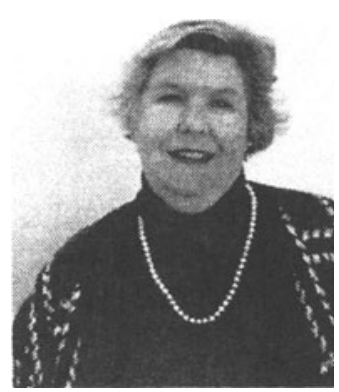

Gail Marshall has measured both the quantitative and qualitative aspects of many innovations. She was a Divisional Assistant in the Division of Research and Evaluation, St. Louis Public Schools, St. Louis, MO, where she evaluated the Urban Consumer Education program, the Follow Through program and the Law-at-Work program. As a member of the evaluation team for the Comprehensive School Mathematics Project (CSMP) she studied both quantitative and qualitative aspects of the project's implementation. A developer of nationally recognised problem-solving software for Sunburst Communications, she has studied children's learning in technology-equipped settings. A member of IFIP WG 3.5, she is currently the software reviewer for Education Technology Monitor and the International Editor of Leading and Learning with Technology, a publication of the International Society for Education. 